This is a provisional PDF only. Copyedited and fully formatted version will be made available soon.

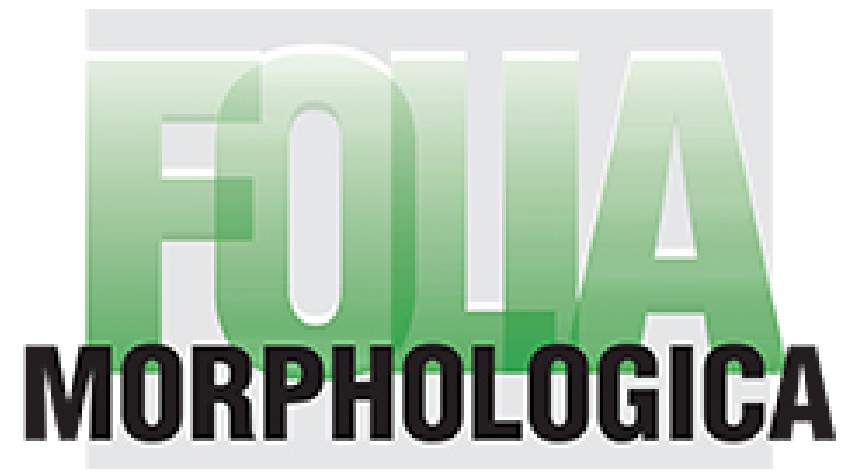

ISSN: 0015-5659

\title{
Bilateral accessory head of the adductor longus muscle: an anatomical case study
}

Authors: T. Kozioł, M. P. Zarzecki, W. Przybycień, W. Twardokęs, J. A. Walocha

DOI: $10.5603 / F M . a 2022.0015$

Article type: Case report

Submitted: $2021-12-05$

Accepted: $2022-01-17$

Published online: 2022-02-17

This article has been peer reviewed and published immediately upon acceptance.

It is an open access article, which means that it can be downloaded, printed, and distributed freely, provided the work is properly cited.

Articles in "Folia Morphologica" are listed in PubMed. 


\section{Bilateral accessory head of the adductor longus muscle: an anatomical case study}

T. Kozioł et al., Adductor longus accessory head

T. Kozioł ${ }^{1}$, M.P. Zarzecki ${ }^{1}$, W. Przybycień ${ }^{1}$, W. Twardokęs ${ }^{2}$, J.A. Walocha ${ }^{1}$

${ }^{1}$ Department of Anatomy, Jagiellonian University Medical College, Krakow, Poland

${ }^{2}$ Department of Histology, Cytophysiology and Embryology, Faculty of Medicine in Zabrze, University of Technology in Katowice, Zabrze, Poland

Address for correspondence: Dr. M.P. Zarzecki, MD, Department of Anatomy, Jagiellonian University Medical College, ul. Kopernika 12, 31-034 Kraków, Poland, tel/fax: +48 12422 95 11, e-mail: michal.zarzecki@uj.edu.pl

\footnotetext{
Abstract

The adductor longus muscle, with its proximal origin at the pubic bone and distal at the linea aspera, is reported to be one of the most frequently injured groin muscles in contact sports, namely football or ice hockey. Notwithstanding, there is a scarcity of published works regarding the accessory heads of the adductor longus muscle in the existing literature, let alone the clinical significance of the said variant.

The following study is a case report describing bilateral accessory heads of the adductor longus muscle in a 97-year old female cadaver. A routine cadaveric dissection revealed two accessory heads on the right thigh and one on the left thigh of a donor with no known structural or pathological abnormalities of the proximal lower extremity. The anterior division of the obturator nerve provided nerve supply to the variants on both sides. The deep femoral, superficial external pudendal, femoral vessels were responsible for the vascular supply to the accessory heads of the adductor longus.
} 
Undoubtedly, extensive knowledge regarding the variant anatomy of the hip adductor muscles is of immense importance to physiotherapists and orthopaedists treating patients for their injury or complete tears. Nonetheless, there is little information regarding the accessory heads of the adductor longus in the existing literature (originating mostly from cadaveric studies) that requires further evaluation in vivo to assess whether this variant might have an impact on a patient's everyday life.

Key words: adductor longus, anatomical variation, anatomy, orthopaedics, physiotherapy

\section{INTRODUCTION}

There are six distinct adductor muscles of the hip, found at the proximal end of the lower extremity in humans that include the adductor longus, adductor magnus, adductor brevis, gracilis, pectineus and obturator externus muscles. The adductor longus muscle has been found to be the most common muscle to be injured, occurring in approximately $62 \%$ in a study of 55 cases of groin injuries [15]. The said muscle has its proximal attachment at the pubic bone, inferiorly to the pubic tubercle, travels anteriorly as a fan-shaped muscle covering the adductor brevis and the middle part of the adductor magnus to its distal attachment at the middle third of the linea aspera of the femur [9]. Moreover, the adductor longus forms the posterior wall of the adductor canal (alongside the adductor magnus) through which the femoral artery, femoral vein, and saphenous nerve pass towards the popliteal fossa, as well as nerve to vastus medialis [9]. A branch from the anterior division of the obturator nerve (originating from the L2-L4 levels of the spinal cord) is said to be responsible for its innervation [9].

The obvious function of the adductor longus is to provide adduction of the thigh. Nonetheless, the aforementioned muscle has also been found to play an important role in hip flexion, as well as internal and external rotation on limited flexion angles [12]. A study by Hides et al. [3] has found the adductor magnus muscle to be involved to a greater extent in weight-bearing closed chain exercises compared to the adductor longus. Henceforth, the aforementioned types of exercise would not be beneficial in training the latter muscle. The 
adductor longus action is best noticeable during flexion of the hip in the hip extension position, whereas the adductor magnus works indifferently to the position of the hip [5].

Injuries to the groin, and especially the hip adductor muscles, occur frequently in athletes and contact sports. Extensive knowledge regarding these muscles and their variant anatomy and function is of immense importance to medical professionals and physiotherapists worldwide, as it may help devise a prevention programme (with appropriately directed exercises to strengthen these muscles) or provide adequate treatment upon injuries [3]. Henceforth, the purpose of this case report was to provide a thorough description of bilateral accessory heads of the adductor longus muscle, encountered during a routine cadaver dissection and to provide an up-to-date overview of the clinical implications pertaining to this muscle.

\section{CASE REPORT}

A routine cadaver dissection of a 97-year old Polish female formalin fixed donor was undertaken at the Department of Anatomy, Jagiellonian University Medical College in Cracow, Poland in November 2021. The procedure was performed on previously untouched lower extremities. Three prosectors (TK, MPZ, JAW) were responsible for the specimen preparation. No visible trauma or other pathology were noted upon their inspection, nor were they found in the available medical records of the patient. Having removed the skin, the subcutaneous tissue and muscular fascia were carefully removed to individually expose the muscles of the thigh. Upon closer inspection of the adductor group of both right and left lower extremities, there were bilateral variations noted regarding the adductor longus muscle. Measurements of the vascular length were obtained with the help of a digital calliper, averaged from 3 separate measurements.

On the left lower extremity, the adductor longus comprised 2 distinct heads. The proximal insertion point of both heads was located close to the pubic tubercle at the inferior pubic ramus, with the typical head attached more medially than the lateral head. The typical head appeared more muscular in its form, with tendinous attachments visible in the close proximity of the inferior pubic ramus, whereas the lateral head had a more tendinous proximal attachment. The distal insertion point for both heads was at the linea 
aspera of the femur, with the lateral head attached superiorly to the typical head. The saphenous vein crossed both of the heads anteriorly. The lateral head was located posteriorly and laterally from the typical head.

Both of the aforementioned heads of adductor longus muscle were innervated by the anterior division of the left obturator nerve. The vascular supply to both the typical and lateral heads was derived from the deep femoral artery (a single branch for both of them), with its length to the lateral head being $18.87 \mathrm{~mm}$ on average, and $25.69 \mathrm{~mm}$ to the typical head. The average length of the femoral artery (measured from the femoral canal to the branching off point of the deep femoral artery) was $72.65 \mathrm{~mm}$.

(Figures 1-2)

On the right lower extremity, the adductor longus comprised 3 distinct heads. All of them had a common origin at the inferior pubic ramus, close to the pubic tubercle. The lateral accessory head had a more tendinous proximal attachment, located most laterally of the three, whereas the middle accessory head, also with a tendinous attachment, was positioned in between the lateral head and the typical head of the accessory longus muscle. The proximal attachment of the typical head appeared to be more muscular in its form, with tendinous attachments visible in the close proximity of the inferior pubic ramus. The distal attachment of all three heads was at the middle $2 / 3$ of the linea aspera of the femur, with the lateral head located most superiorly, and the typical head most inferiorly. The typical and lateral heads were crossed by the saphenous vein anteriorly, whereas the middle head was located deep in between the two other heads. The lateral head was positioned posteriorly and laterally from the typical head, whereas the middle head was located the most posteriorly and in between the two said structures.

All three aforementioned heads were innervated independently by the anterior division of the obturator nerve. The average length of the femoral artery (measured from the femoral canal to the branching off point of the deep femoral artery) was $73.44 \mathrm{~mm}$. The typical head had a dual vascular supply. A branch of the deep femoral artery to the typical head was $31.48 \mathrm{~mm}$ in length and reached the middle part of the muscle, whereas a small branch from the femoral artery $14.69 \mathrm{~mm}$ in length supplied the inferior part of the muscle. The middle head obtained its vascular supply also from the deep femoral artery that was $27.67 \mathrm{~mm}$ in length. The vascular supply for the typical and middle head originated from 
the same branch. The lateral head also had a dual supply. Its superior part was derived from the superficial external pudendal artery and veins that were $40.07 \mathrm{~mm}$ in length from their origin point at the external pudendal vessels. The inferior part was supplied by a branch from the deep femoral artery that was $16.59 \mathrm{~mm}$ in length, and originated separately from the branch that supplied the typical and middle head.

(Figure 3)

Unfortunately, the average lengths of the respective heads on both sides were not measured, as that would require for the surrounding muscles to be excised in order to obtain wide access and reliable measurements from their proximal to their distal insertion points.

\section{DISCUSSION}

The current study reports a case of bilateral accessory heads of the adductor longus muscle, 2 on the right and 1 on the left. Their vascular supply was chiefly derived from the deep femoral artery, but also from the superficial external pudendal artery and the femoral artery. The available literature of the subject suggests that the adductor longus may also be vascularised by the obturator arteries $[13,14]$, but the authors have not found any of the said branches in the current study.

There is scarcity of research regarding the accessory heads of the adductor longus muscle in the available literature. Tuite et al. [17] are the only authors that made a brief mention about bicephalic adductor longus. The study was based on 37 cadaveric observations and investigated variations in the proximal tendinous origin and the typical muscle's length. Most of the described cases had tendinous attachments on the anterior surface, but on the posterior side it was usually muscular in origin [17]. The aforementioned authors also reported other types of anomalies, such as adductor longus muscular origin on the anterior surface or fused proximal tendons of the adductor longus and the gracilis muscles [17].

There are works $[11,14]$ that noticed the possibility of adductor longus having two distinct parts, however access to the primary source of this information turned out impossible. The second variation also mentioned in several sources is the muscle's length 
$[11,14]$. In some uncommon cases, the adductor longus may even reach as far as the knee and fuse with the adductor magnus tendon [11]. Du Plessis et al. [11] reported that in this situation the tendons of the adductor longus and the adductor magnus can be fused together.

The clinical significance of the adductor longus muscle has been described only in a few case reports. The most frequent condition involving the aforementioned anatomical entity is its total rupture, which occurs mostly in football players $[8,10]$. Incomplete tears or strains happen frequently at the more susceptible parts of the muscle, i.e. at its proximal part on the junction point of muscular and tendinous fibers or else at its insertion on the pubic bone. However, complete muscle tears occur more often at the distal attachment to the femur [15]. Injury to the adductor longus is also common in sports such as ice hockey, horseback riding, skating and hurdling [17].

Nonetheless, sport injuries are not the only disorders associated with the adductor longus muscle. Alimehmeti et al. [1] described an unusual case of saphenous neuropathy due to a hydatid cyst located in the adductor longus, that caused swelling, numbness and pain in the medial part of the right tight. The cyst was excised and the patient walked independently the next day after the procedure. Another example of a non-traumatic disorder is urinary bladder cancer metastasis to the adductor longus [7]. The 62-year old male patient in question presented with unusual symptoms in the right thigh, namely pain, swelling of the extremity and struggled with mobility. Unfortunately, the patient died during treatment, hence there is not enough information to estimate how the metastasis would have impacted his gait and muscle activation.

Accessory muscles are usually asymptomatic, but sometimes they may present clinical symptoms $[16,18]$. Various cases of supernumerary muscles have previously been reported in the thigh and knee area, e.g. the tensor vastus intermedius [2], accessory sartorius muscle [6], tensor fasciae suralis, accessory semimembranosus muscle or accessory popliteus muscle $[16,18]$. Accessory muscles can cause nerve entrapment syndromes, vascular compressions or may mimic other pathologies, namely soft tissue tumour or the Baker's cyst [18]. Truly, the clinical symptoms associated with presence of a supernumerary muscle depend on its location and the neighbouring neurovascular entities involved. Clinical deduction derived from cadaveric studies is extremely difficult 
and poses a high risk of bias, as most often encountering some of the anatomical variations occurs incidentally, without the previous knowledge of the patient or their family of their existence. Therefore, lack of medical history with the description of potential symptoms makes it impossible for cadaveric studies to truly discern the clinical meaning of the finding, hence it remains only as an assumption.

Generally speaking, the adductor longus muscle does not have an extensive description of its anatomy and clinical considerations in the available literature. Most of the publications describe its traumatology, biomechanics and therapeutic management in injuries. The reason behind it may potentially be low clinical importance of anatomical variations in this area. More research, and on a larger scale, regarding the anatomy of the adductor longus is still needed to estimate the prevalence of its accessory heads. The authors in their dissection experience have not encountered the described here variation in the past, regardless of its laterality, hence presume that its prevalence is rare. Both clinical and biomechanical properties of the accessory heads of the adductor longus would be beneficial to ascertain its potential role in the human organism. Nonetheless, the authors would like to acknowledge Żytkowski et al. [19] in saying that although the so-called 'anatomical norm' proves beneficial in everyday medical practice by presenting the most common anatomy of a structure, it is also a double-edged sword as it may also present an overly idealised view.

\section{CONCLUSIONS}

Anatomical variations of the adductor longus muscle play a crucial role whilst assessing a groin injury in contact sports, but also in case of cysts and casuistic neoplastic metastasis to the muscle. Undoubtedly, a thorough knowledge is required from medical professionals to adequately diagnose and treat such patients. This is most probably the first study to report bilateral accessory heads of the adductor longus muscle (with two accessory heads on the right thigh) thus adding to the existing literature and pointing to the yet still needed further scientific exploration of the said muscular variation in vivo.

\section{Acknowledgements}


The authors are indebted to Mr Jacenty Urbaniak for the technical support. “The authors sincerely thank those who donated their bodies to science so that anatomical research could be performed. Results from such research can potentially increase mankind's overall knowledge that can then improve patient care. Therefore, these donors and their families deserve our highest gratitude” [4].

Conflict of interests: None declared

\section{REFERENCES}

1. Alimehmeti R, Seferi A, Rroji A, Alimehmeti M. Saphenous neuropathy due to large hydatid cyst within long adductor muscle: Case report and literature review. J Infect Dev Ctries. 2012; 6:531-535, doi: 10.3855/jidc.1766

2. Franchi T. Tensor vastus intermedius: a review of its discovery, morphology and clinical importance. Folia Morphol. 2020 (ahead of print), doi: 10.5603/fm.a2020.0123

3. Hides JA, Beall P, Franettovich Smith MM, Stanton W, Miokovic T, Richardson C. Activation of the hip adductor muscles varies during a simulated weight-bearing task. Phys Ther Sport. 2016; 17:19-23, doi: 10.1016/j.ptsp.2015.06.001

4. Iwanaga J, Singh V, Ohtsuka A, Hwang Y, Kim HJ, Moryś J, Ravi KS, Ribatti D, Trainor PA, Sañudo JR, Apaydin N, Şengül G, et al. Acknowledging the use of human cadaveric tissues in research papers: Recommendations from anatomical journal editors. Clin Anat. 2021; 34:2-4, doi: 10.1002/ca.23671

5. Kato T, Taniguchi K, Akima H, Watanabe K, Ikeda Y, Katayose M. Effect of hip angle on neuromuscular activation of the adductor longus and adductor magnus muscles during isometric hip flexion and extension. Eur J Appl Physiol. 2019; 119:1611-1617, doi: 10.1007/s00421-019-04150-5

6. Kim J, Lee JH. A unique case of an accessory sartorius muscle. Surg Radiol Anat. 2019; 41(3):323-5, doi: 10.1007/s00276-018-2155-5 
7. Koca I, Ucar M, Bozdag Z, Alkan S. Adductor longus muscle metastasis of transitional cell carcinoma of the urinary bladder. BMJ Case Rep. 2014; bcr2014203768, doi: 10.1136/bcr-2014-203768

8. Masionis P, Popov K, Kurtinaitis J, Uvarovas V, Porvaneckas N. Surgical treatment of the adductor longus muscle's distal tendon total rupture in a soccer player. Orthop Traumatol Surg Res. 2016; 102:673-676, doi: 10.1016/j.otsr.2016.03.011

9. Lower limb. In: Moore K, Dalley AI, Agur A (ed.). Moore Clinically Orientated Anatomy, 7th ed. Lippincott Williams and Wilkins, Baltimore / Philadelphia 2014: 548-556.

10. Peterson L, Stener B. Old total rupture of the adductor longus muscle. A report of seven cases. Acta Orthop Scand. 1976; 47:653-657, doi:

$10.3109 / 17453677608988754$

11. du Plessis M, Loukas M. Thigh muscles. In: Tubbs R, Shoja M, Loukas M (ed.). Bergman's Comprehensive Encyclopedia of Human Anatomic Variation, 1st ed. Wiley-Blackwell, Hoboken, NJ, USA 2016: 415.

12. Pressel T, Lengsfeld M. Functions of hip joint muscles. Med Eng Phys. 1998; 20:50-56, doi: 10.1016/S1350-4533(97)00040-4

13. Ransom AL, Sinkler MA, Nallamothu SV. Anatomy, Bony Pelvis and Lower Limb, Femoral Muscles. [Updated 2021 Oct 6]. In: StatPearls [Internet]. Treasure Island (FL): StatPearls Publishing; 2021 Jan-. Available from: https://www.ncbi.nlm.nih.gov/books/NBK500008/

14. Reicher M, Łasiński W. Mięśnie uda. In: Bochenek A, Reicher M (ed.). Anatomia Człowieka. Volume I, 6th ed. Państwowy Zakład Wydawnictw Lekarskich, Warszawa 1990: 875-876.

15. Renstrom P, Peterson L. Groin injuries in athletes. Brit J Sport Med. 1980; 14:3036, doi: 10.1136/bjsm.14.1.30 
16. Sookur PA, Naraghi AM, Bleakney RR, Jalan R, Chan O, White LM. Accessory muscles: Anatomy, symptoms, and radiologic evaluation. Radiographics. 2008; 28:481-499, doi: 10.1148/rg.282075064

17. Tuite DJ, Finegan PJ, Saliaris AP, Renström PAFH, Donne B, O’Brien M. Anatomy of the proximal musculotendinous junction of the adductor longus muscle. Knee Surgery, Sport Traumatol Arthrosc. 1998; 6:134-137, doi: 10.1007/s001670050086

18. Vanhoenacker F, Desimpel J, Mespreuve M, Tagliafico A. Accessory muscles of the extremities. Semin Musculoskelet Radiol. 2018; 22:275-285, doi: 10.1055/s-00381641575

19. Żytkowski A, Tubbs RS, Iwanaga J, Clarke E, Polguj M, Wysiadecki G. Anatomical normality and variability: Historical perspective and methodological considerations. Transl Res Anat. 2021; 23:100105, doi: 10.1016/j.tria.2020.100105

Figure 1. A left accessory adductor longus head with its neural supply; 1 . Adductor longus; 2. Adductor longus accessory head; 3. Obturator nerve (anterior division); 4. Branch of the obturator nerve to adductor brevis; 5 . Branch of the obturator nerve to the adductor longus accessory head; 6 . Branch of the obturator nerve to the adductor longus.

Figure 2. A left accessory adductor longus head with its vascular supply; 1 . Adductor longus; 2. Adductor longus accessory head; 3. Femoral artery; 4. Branch from the deep femoral artery to the adductor longus and its accessory head.

Figure 3. Two right accessory adductor longus heads; 1. Adductor longus; 2. Adductor longus lateral accessory head; 3. Adductor longus middle accessory head; 4. Gracilis muscle; 5. Femoral artery 


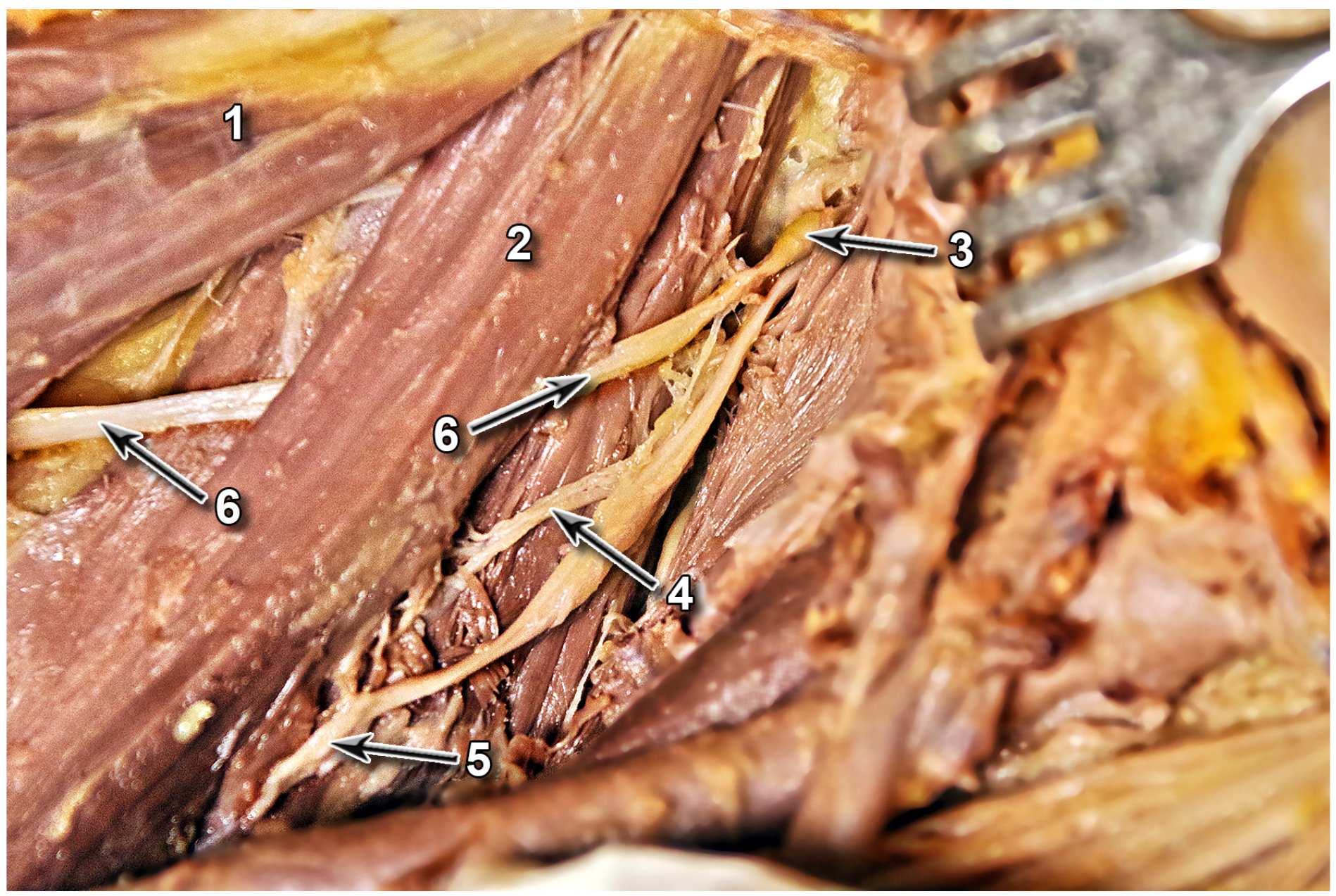




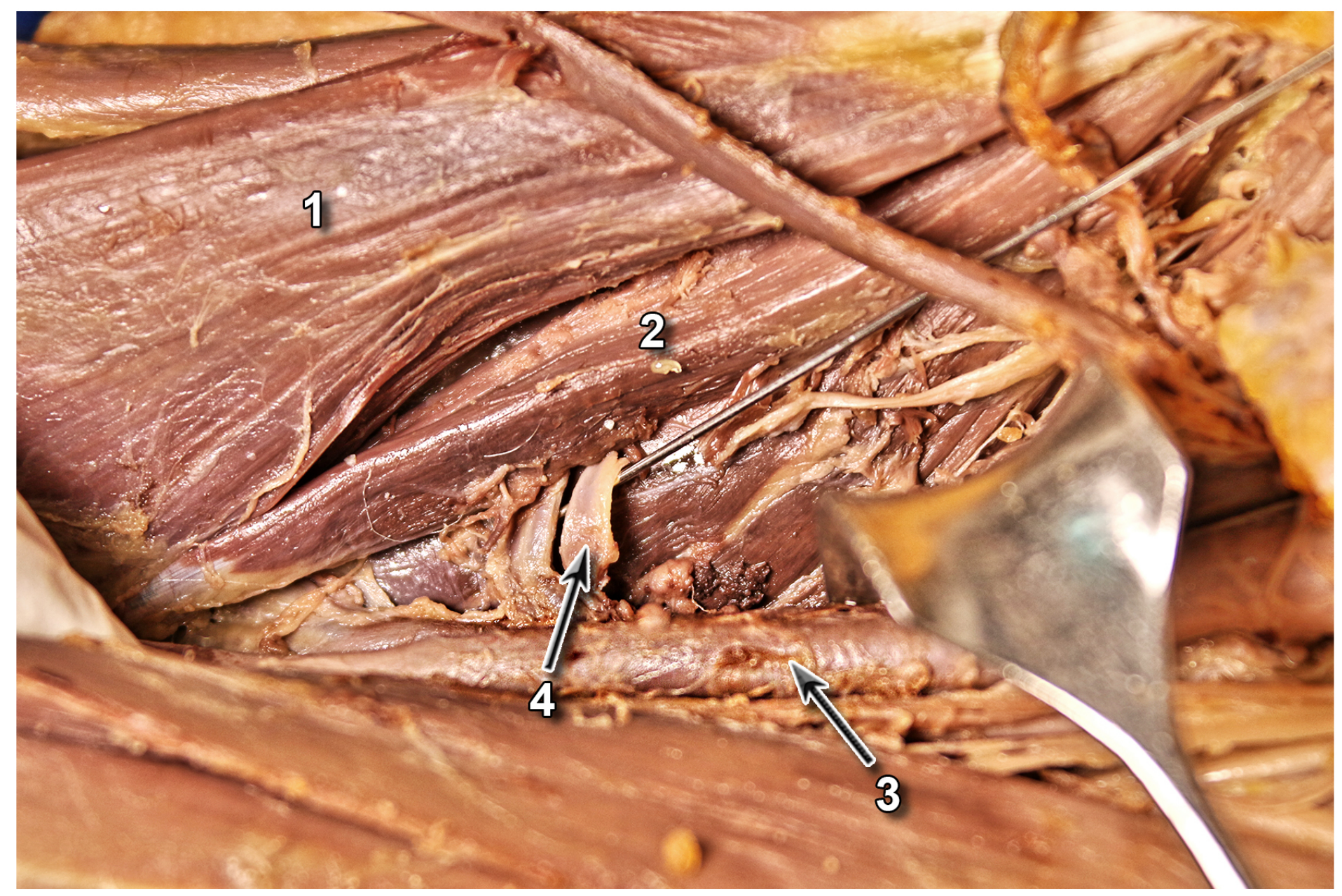




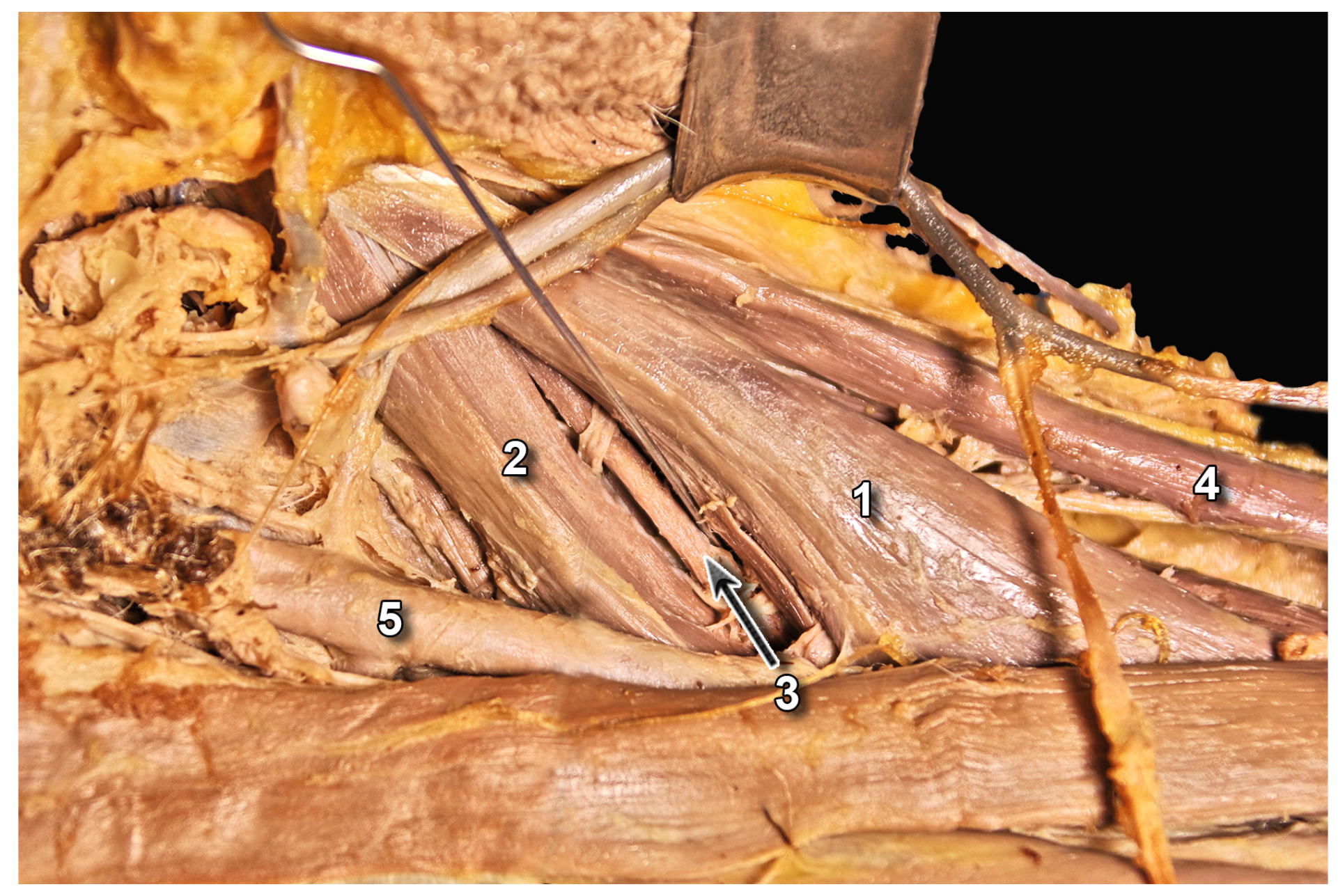

